\title{
Paid Academic Services With Mercy And Compassion: Phenomenologizing The Lived Experiences Of Research Mercenaries In The Philippines
}

\author{
Romiro G. Bautista ${ }^{a}$ \\ ${ }^{a}$ Graduate School, Quirino State University, Philippines

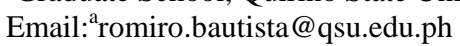

Article History: Received: 10 November 2020; Revised 12 January 2021 Accepted: 27 January 2021; Published online: 5 April 2021

\begin{abstract}
Research, in the midst of internationalization of education, becomes one of the most prolific areas of the criteria for teacher retention and promotion in the academia; however, issues and concerns had sprung since then as to authorship authenticity because of the mushrooming of research mercenaries. This study is designed to explore the indulgence of research mercenaries in their quest of helping their protégées in exchange of reasonable costs. Qualitative data were gathered from the informants' interview. Data were processed through document trail among the informants to ascertain the veracity of the transcribed responses, reflections, and observations. Thematic analysis revealed four themes on the experiences of research mercenaries: need to augment income, mercy and compassion, professional indulgence, and research, the IN thing to be promoted. It is concluded that research mercenaries are working in a symbiotic manner among their protégées where they adopt them as their academic disciples and this practice will continue to flourish until there is inequity on the capacity of professionals on the academic work and works that they do
\end{abstract}

Keywords: Research Mercenaries, Academic Research, Faculty Promotion.

\section{Introduction}

The dawn of the new educational era at the forefront of academic integration in various topographies of the world has driven academic planners to intensify the faculty portfolio with research qualifications. Hence, both the Department of Education (DepEd) and State College and Universities (SUCs) adopt mechanisms to appraise their faculty performances where research plays a great role in faculty retention and promotion, i.e., research is a criterion for Master Teacher position in DepEd, and a research publication to Web of Science (Clarivate analytics) and SCOPUS indexed journals or to Commission on Higher Education (CHED) accredited journal is a criterion in professorial accreditation in SUCs. Anchored on these tight-knit criteria on faculty portfolio is the research culture that is introduced in the academic community where one belongs vis-à-vis their working conditions. Hence, professionals in the academe are forced to imbibe a retention and promotion culture beyond their expertise.

Moreover, the current educational criteria on faculty retention and promotion included the research criteria where only few can comply because of technical knowledge and expertise $[1,2,3]$. The conflict on the inclusion of the research criteria in the faculty portfolio threatens academic honesty among faculty members by coveting the services of research mercenaries. Burdened by the proofs of incapability on some criteria particularly in research and research publication, teachers tend to join the niche of promotion which pass is sometimes derived from a mockery of intellectual cognition - the research mercenaries.

Apparently, professionals, who call themselves as mercenaries, flourish in the academic community by offering technical and expert consultancy and services. Such services are equated to monetary consideration agreed between the contracting parties. This concordance around the world is no longer new in the academic community as we are in the era of capacity builders [4]. This era is stemmed from Human Capability Approach which underscores the idea of capacity from the kind act of helping other professionals that is brought about by the colonizing inequity of capability, technical knowledge, and professional experiences [5]. It was claimed that capacity builders create a curated and connected relationships and intellectual cross-pollinations between mentors and mentees; hence, working in a symbiotic relationship towards a certain academic goal [6].

The crux is: research mercenaries flourish in our topography because of the conflict that limits the existence of other potential professionals for promotion who are not academically or technically prepared to deliver such output. It is in these realms that the indulgence of research mercenaries is tapped by some professionals who are willing to pay in exchange for an academic qualification in upgrading their faculty portfolios in conjunction with the relatedness of the criteria of a particular evaluation. In the locale of this study, many are seeking the help of the so-called research mercenaries to easily comply with the stiff requirements of such advanced studies. Many researchers also claim that there is a decline in the interest of many students in the advanced programs towards 
thesis writing. Moreover, these research mercenaries are spawning across the landscape like an ordinary business entity.

\subsection{Objectives of the Study}

This study explored the experiences of academic mercenaries in their act of helping their academic protégées in exchange of a reasonable cost. Specifically, this study sought to (1) document their experiences in accepting academic protégées in research and (2) capture factors that contributed to their continued academic business in research and research publications.

\section{Methodology}

This study employed the Qualitative Research Design using Phenomenology as strategy for inquiry. The informants, where qualitative data were generated, are academic mentors who contract other authors to conceptualize, write, and package their academic research in exchange of a reasonable cost. To be qualified as informants of the study, they must have had research projects in the past three years be it a thesis, dissertation, action research, or research article publishing. Informants explained their experiences including a configural mode of understanding and principles - the meanings of their stories and experiences as part of an identity development [7].

I personally interviewed the informants to gather the data needed in the study. Before the interview was conducted, I briefed the informants that their participation in the interview is voluntary and they can terminate it anytime. A consent form was signed by the participants. Transcripts of the interview were carefully transcribed and coded which were validated by a researcher whose credibility is beyond compare. Audit trail was employed in routing the transcripts of the interview to the informants in ascertaining the veracity of the claims. Audit trail is an in-depth approach to illustrating that the transcripts are based on the participants' narratives. It also involved a description on how the data were gathered and analyzed [8,9]. Henceforth, the data are considered verified and valid.

Data were analysed thematically to conclude on the research objectives. Themes are formulated according to the recurring claims of the informants which served as bases in an inquiry-based analysis vis-à-vis the research problem. Aptly, the analysis done in the research includes familiarization and organization, coding and recoding, and summarizing and interpreting [10].

\section{Results and Discussion}

The following themes were formulated based on the gathered data in an inquiry-based analysis vis-à-vis the research problem.

Financial augmentation. It is a natural phenomenon that a person will find relief(s) in times of inadequacy. As such, individuals are tempted to make extra income to augment their finances in order to make their lives better not only for themselves but for their family, as well.

In the foregoing context, mercenaries' act of providing such services among their protégées is centred on their self-interest. However, this concordance is prompted to whether this is morally right or wrong, or is it professionally prim and proper?

One might underscore the fact that they do it at their own advantage. Theoretically, it is a natural phenomenon if one acts to his own advantage - perhaps a financial return, elevation from the eyes of others, and a sense of selfactualization. Owing to these courses of reasons, one's act in his own interest is not considered morally wrong but neutral, or of no moral worth at all $[11,12]$. In the interest of psychological egoist, one finds pleasure in serving his own good and as a rational being, he has to find ways to elevate his status, recuperate from life's adversaries at the ingenuities of his command. Moreover, enlightened egoists claimed that serving our own good entails hardwork towards life's long-term fulfillment and it is in this manner where they can fulfil their needs and pleasure $[11,12,13]$. Hence, in the state of the academic mercenaries, they do not have any moral burden but the burden of proof lies on their protégées in terms of the professional implications of this act.

The following transcripts on the informants' interviews qualify the claim of this study that their act of giving academic mercies is a natural phenomenon of augmenting their financial needs and of no moral worth:

Mercenary X

“... I do not feel any guilt as mine is rendered 'quality service' (with emphasis). On the issue of academic dishonesty? I think the issue is on their part, not mine! I need some money to augment my meagre income and I believe my business is prim and proper... hmmmm... Of course, you know how sad the salary of teachers here in the country. You always need to have extra-income to survive..." 
Mercenary U

“... Let us face it. There is no free service nowadays! Crafting a 'sound research' is a tedious thing to do, a laborious mental activity. I assure them that the research that I will give is something that they can be proud of. My protégées are winners in conferences. You know, this act is equated to their promotion; so, they need to pay me in exchange of my services. I also need some financial augmentation (smiles...) I am already retired and I have (more) needs. As to the moral thing of my services? I have personal reservations but professionally? Hmmm... not at all..."

Mercenary Y

“... I did not bite the idea (at first) because I did not want to be in the helm of prostituting research. I was a little bit perplexed as the rate was significantly high. Eventually, I was enticed with it because I need money (who does not need it anyway!). What can I do? Doing it (theses/dissertation/action research) entails a lot of doing. Thus, my efforts must be compensated. Professional burden? Not mine..."

\section{Mercenary Z}

“... Of course, the primary consideration here is the financial thing - fast and manageable work for financial augmentation. Well... I was perplexed at times as everybody is in for a financial constraint but what can I do: it is the name of the game. They do not have the expertise in doing one. They sought my services. So, the professional burden is not mine..."

Mercy and compassion! It is a natural phenomenon that one is prepared while others are not. In the course of this study, some are born to be writers while others are not.

The world of the research mercenaries is governed by the concept of symbiosis encroached by a conflict of utility. The lives of teachers are always found in a gamut of change; it is just but normal for them to implement something new. Sometimes, they are not even prepared in doing so, i.e., research. Academic research of technical rigor, as claimed by some researchers, entails expertise and preparation and this is where the research mercenaries are coming into the $[14,15,16]$.

Aptly, the current educational era is confronted by the conflict of crafting a research of academic rigor. In view of the Conflict Theory, the inequality in terms of academic preparation on research writing has made a significant conflict on the interests of many teachers. This conflict on knowing to conduct research is a natural phenomenon among teachers: a conflict that must not draw strata among them. Hence, teachers must be given equal opportunities in shaping their abilities towards equity in faculty retention and promotion [12, 17]. In the current promotional scheme, research plays an important role that curtails other promising teachers' promotion because they are not in for research despite their want to be promoted as it calls for a greater relief: greater salary, greater monetary relief for their family.

Amidst this conflict is the utility offered by the research mercenaries where they can enjoy similar opportunities as enjoyed by others; thus, eliminating the strata created by the conflict made by the insertion of research in the faculty portfolio. In the context of the research mercenaries, they are confronted with mercy and compassion in the course of their pursuit of helping their protégées in a symbiotic manner - learning to exist in an organization at the helm of a utility that addresses a conflict. Symbiosis, in this sense, integrates liberal education and improved relationships between mentee and mentor towards a shared goal. This shared goal of intellectual works and inspiration are traced in the Philosophy of Plato and Aristotle - the search for intellectual commons. This, in the current era, is called new knowledge management regime that rationalized the mentoring program stemming into greater productivity $[18,19]$.

The following transcripts on the informants' interviews qualify the claim of this study that their pursuit of helping their protégées entails mercy and compassion:

\section{Mercenary X}

“... As I have said, I pity them. This is not only about money, it is mercy and compassion: an act of having compassion to my protegees as they are not prepared to what they are expected to deliver. It is my policy that they should never come back for another transaction after my services because I see to it that I teach them how to do one. This is not just money. I teach them the technicalities of research so they can profess research culture especially that they are in the academe. At first, they really paid my services but after that they just come for some consultations. So, they may come and visit me for technical advices as I do not want them to become dependent forever. I am happy that they learned a lot from me as I consider them as my academic disciples. They are learnable and teachable (of course, they are teachers) - what they need is extra effort in teaching them how to 
make one (research with academic rigor). I think this is the problem, it is not that they do not know about it but they do not have time and the right technique. Most of my protegees are still consulting up to now and I am happy to where they are now ..."

Mercenary U

“... Yeah! I know it. I pity them at times. Part and parcel of my work is the pleasure of seeing one who is promoted and enjoying the perks of this academic venture. This is symbiosis: I need money and they need my services. For me, these teachers need consideration, patience, and kind understanding (with emphasis). Of course, they should not be dependent among us (research mercenaries) as they are also professionals..."

\section{Mercenary $\mathrm{Y}$}

“...Yes. They just do not need help and understanding - they need compassion for they are overworked and forced to do tasks that they lack knowledge and expertise. For sure, they will not seek for academic mercies if they know what they are required by their supervisors and the department, in general. Yet, their work does not end from the 8-hour job as this extends to their homes late up night most of the times. In the midst of these odds, I think their recourse for academic mercenaries is just but normal. The monetary thing is inevitably there but beyond that business is the kind understanding and compassion to their academic weakness. Just remember that not everybody is a writer, a researcher..."

\section{Mercenary Z}

“... Who will say no to a kind request. I cannot say no to a request which I believe is a potential key for a promotion. Just a thought, in exchange of this academic mercy is the future of their family. I have had a number of protegees now since then and most of them are now occupying top positions like Professors, Master Teachers, Head Teachers, Principals, among others..."

Professional Indulgence. Happiness is a perceptible result at the end of a certain course of action. According to Aristotle, happiness is the summum bonum in man; the goodness for the sake of making both parties happy and contented [12]. In case of the research mercenaries, their happiness is not only centred to the money that they get from their expert services but also by their happiness when they see their protégées succeed and progress through research.

Theoretically, research mercenaries look at the object at the end of their act of offering mercies to their protégées - the call of indulgence in perpetuating the science of research. This is in concordance with the Theory of Teleology which qualifies how ends are ordered in relation to each other or how each thing is ordered to its end [20]. Research mercenaries look at the essential end after their courses of action - their academic disciples who continue doing research. They offer invaluable input to those who really wanted to learn.

Despite these, research mercenaries co-exist with their protégées in symbiotic manner. Trying to benefit from each other, research mercenaries raise amounts that bring relief to their needs from their expertise and qualifications while their protégées are enabled to participate in an avenue where they lack knowledge and expertise, i.e, being promoted from an output made or supervised by somebody else. Still, this conflict is rooted to the strata brought by the inclusion of a criterion that only few can play.

The following transcripts on the informants' interviews qualify the claim of this study that their pursuit of helping their protégées is centred to their indulgence in perpetuating research:

Mercenary Y

“... There are two types of clients here: those who need a ghost writer and those who just need a consultant. Both need my indulgence as a consultant. As professionals, we cannot do any further for the first type as they already about to be retired (so, they just simply pay in exchange of their deficiency). All we need to do is to extend our help with kind-professional assistance and understanding among the protegees from the second type as they are the young professionals who will be the next researchers. I am happy that they respond to such encouragement - just boost their morale and provide the necessary technical assistance. For sure, they will go for an extra mile in their profession..."

\section{Mercenary U}

“...You know what? My job is not only to raise money for my own interest, I also raise awareness among my protégées. They plan to conduct research in less perspectives (Definitely, no readership). There is no leverage this is where I am coming from. I pity them as they are not aware of the research trends. In my case, I make them aware of the research tracks that will definitely earn readership and interest to international platforms - both in research conferences and publication..." 
Mercenary Z

“... You know, this is not just about money. I extend help in exchange for money (Yes!). However, part of that contract is my assurance that I seeded in them the essence of helping others and the perpetuation of loving research. At any rate, my services are free of charge to those who are really serious about this academic venture. I am happy that (still) there are professionals who want to quench their thirsts for knowledge, those who want to learn...,

\section{Mercenary X}

“... Yes! I got remunerable income from this venture; however, part of this job is to promote research. I always extend my services of lecturing them how the research was done. But do you know what hinders them from doing their own research? Most of them are no longer interested to know how to do it. All they need is to successfully defend their thesis or dissertation, to present an action research, and to publish their research articles so they can be promoted..."

Research... The IN thing to be promoted! The concept seen by every teacher for promotion is the idea that greater salary, greater relief. Hence, part of their motivation to be promoted is the financial reward and the accompanying prestige that this promotion can bring $[1,2,3]$. It is in this context that despite their incapability in doing research is the idea to co-exist with other professionals - the desire to be promoted is fuelled by the basic psychological needs for autonomy and relatedness.

The Theory of Reasoned Action explicates that the inner drive of an individual, as motivation, affects his action and intention. This further affects his performance and work-related behavior. Among the tenets of this theory are (1) the more favorable the attitude of an individual toward a behavior, the stronger will be the intention of the individual to engage in the behavior; (2) the greater the subjective norm, the stronger the intention of the individual to perform the behavior; and (3) the stronger the intention of the individual to engage in a behavior, the more likely the individual will be to perform it [21].

Hence, in the midst of the conflict brought by the inclusion of research in the faculty portfolio, which is participated in by a few, is the idea to tap mercenaries. Many are tapping the help of research mercenaries in order for them to see and feel the essentials of their existence in the academe.

The following transcripts on the informants' interviews qualify the claim of this study that research is the IN thing for promotion:

Mercenary U

“... Let us face it. Teachers are governed by criteria that only few can comply. They wanted to be promoted but they cannot comply. Others plan to conduct research in a less perspective (Definitely, no readership). There is no leverage - This is where I am coming from which means, I am here (and will be here) until someone needs my academic mercy and expertise..."

\section{Mercenary X}

“... You know what is wrong in this country? Agencies want their teachers to do research but their teachers are burdened with professional tasks which extends to their homes including their vacations. Well... it is the name of the game - PROMOTION! If only systems are just like ours before (referring to an International University) then everybody might be motivated to do research - deloading, travel incentives for presentation and publication, as well as awards and recognition; teachers are well compensated..."

\section{Mercenary Y}

“... Why do they patronize this academic venture? It is plain and simple as PROMOTION. It is because they are overworked plus take-home works; yet, they need to comply for the provisions of their promotion. Who will be able to do research tasks in this kind of working conditions? In the basic education, aside from being overworked, Teachers have piles of paper works to accomplish plus other related works and home visitation during their vacation. Another issue here is their preparation and training. Furthermore, does our system provide program for those who are not prepared to be one - to be a researcher?"

Mercenary Z

"... It is plain and simple. It is because everybody wants to be promoted - whether they come from the Basic Education or Higher Education, public or private school. Research has revolutionized the promotion criteria for teachers. This is the trend that they will live up to - publish or perish: do research or pay for a research mercenary..." 


\section{Conclusion}

Based on the gathered data from the informants' interview, the following are drawn:

1. Research mercenaries are just like other professionals who need extra income to augment their finances;

2. Research mercenaries play significant role in perpetuation of the science of research as they guide interested professionals to learn the its technicalities;

3. Research mercenaries, at the helm of exchanging their professional and academic services to reasonable cost, are called for their indulgence in helping other professionals to realize their dreams;

Research mercenaries will continue to flourish until some professionals are not well capacitated in doing professional works like research with academic rigor.

\section{References}

Vero, E. (2017). The importance of motivation in an educational environment. Formazione \& Insegnamento, XV(1), 57-66.

Darling-Hammond, L. (2006). Constructing 21st century education. Journal of Teacher Education, 57(3), 300314.

Deci, E., Koestner, R., \& Ryan, R. (2001). Extrinsic rewards and intrinsic motivation in education: Reconsidered once again. Review of Educational Research, 71(1), 1-27.

Getto, G. (2014). Designing for engagement: Intercultural communication and/as participatory design. Rhetoric, Professional Communication, and Globalization, 5, 44-66.

Chiu, C.Y., Gelfand, M., Yamagishi, T., Shteynberg, G., \& Wan, C. (2010). Intersubjective culture: The role of intersubjective perceptions in cross-cultural research. Perspectives on Psychological Science, 5(1), 1-12.

Tabak, R.G., Khoong, E.C., Chambers, D.A., \& Brownson, R.C. (2012). Bridging research and practice: Models for dissemination and implementation. American Journal of Preventive Medicine, 43(2), 337-350.

Hoshmand, L. (2005). Narratology, cultural psychology, and counselling research. Journal of Counselling Psychology, 52(2), 178-186.

Carcary, M. (2009). The research audit trail - enhancing trustworthiness in qualitative inquiry. The Electronic Journal of Business Research Methods, 7(1), 11-24.

Malterud, K (2001). Qualitative research: Standards, challenges, and guidelines. The Lancet, 358, 483-488.

Nowell, L., Norris, J., White, D., \& Moules, N. (2017). Thematic analysis: Striving to meet the trustworthiness criteria. International Journal of Qualitative Methods, 11, 248-258.

Fiori, S. (2005). Individual and self-interest in Adam Smith's wealth of nations. Cahiers d'economic Politique, 2(49), 19-31.

Solomon, R.C. (2000). Morality and the Good Life. New York: Mc-Graw Hill, Inc.

Gert, B. (2000). Hobbes and psychological egoism. Journal of History and Ideas, 28(4), 18-36.

Sanchez, K.L.D., Malinao, C.W.M., \& Bautista, R.G. (2017). University research writing: A burden or a key to success? QSU-CTE Journal of Educational Practices and Standards, 2(1), 10-21.

Jung, A.P. \& Petrella, J.K. (2008). Undergraduate research: importance, benefits, and challenges. International Journal of Exercise Science, 90-94.

Defazio, J., Jones, J., Tennant, F., \& Hook, S.A. (2010). Academic literacy: the importance and impact of writing across the curriculum. Journal of the Scholarship of Teaching and Learning, 34.

Philips, I. (2004). Defending equality of outcome. Journal of Political Philosophy, 12(1), 1-19.

Eikeland, O. (2013). Symbiotic learning systems: Reorganizing and integrating learning efforts and responsibilities in higher education institutions and work places. Journal of Knowledge Economy, 4(1), 98118.

Nowotney et al. (2001). Re-thinkingSscience - Knowledge and the Public in Age of Uncertainty. Cambridge: Polity Press.

Kelemen, D., \& Rosset, E. (2009). The Human Function Compunction: Teleological explanation in adults. Cognition, 111, 138-143.

Fishbein, M. \& I. Ajzen (1975). Beliefs Attitude, Intention and Behavior: An Introduction to Theory and Research. Philippines: Addison-Wesley Publishing Company. 